\title{
Vendor Meeting Material
}

National Cancer Institute

\section{Source}

National Cancer Institute. Vendor Meeting Material. NCI Thesaurus. Code C115615.

A collection of agendas, presentation materials, and other documents generated for attendees during a vendor meeting. 